\title{
Problemática das inUNdações e sua Relação com a Situação das Áreas de Preservação Permanente: Visão do poder público e o uso de geoprocessamento
}

\author{
Ângela Cruz Guirao ${ }^{1}$ \\ Marcelo Fernando Fonseca ${ }^{2}$ \\ Marina Sória Castellano ${ }^{3}$
}

\begin{abstract}
Resumo: Este artigo tem como objetivo analisar a situação das Áreas de Preservação Permanente (APP) no entorno de cursos d'água, no tocante a sua condição de preservação, $e$ verificar a relação deste fato com os eventos de inundações ocasionados por precipitações intensas, utilizando como exemplo o caso da Macrozona 9 (MZ-9) no município de Campinas (SP). O trabalho envolveu a identificação da quantidade de eventos de inundação ocorridos por Unidade Territorial Básica (UTB) na MZ-9 no período entre 1980 e 2007; a delimitação e classificação das APP; a elaboração do Plano de Informação sobre a situação das APP $e$ ocorrências de eventos de inundação por UTB; e uma análise de como o poder público municipal trata das questões associadas aos impactos de chuvas. Os resultados indicaram, principalmente, que nos trechos aonde as APP encontram-se degradadas, ocorre maior quantidade de ocorrências relacionadas aos alagamentos, o que reforça a importância dos Planos Locais de Gestão na proposição de diretrizes e medidas para reduzir e solucionar problemas desta natureza.
\end{abstract}

Palavras-Chave: Precipitação; Impactos Socioambientais; Planejamento Urbano; Geoprocessamento.

\section{The issue of flooding and its relation to the situation of Permanent Preservation Areas: the government's vision and the use of geoprocessing}

\begin{abstract}
This paper aims to analyze the situation of the Permanent Preservation Areas (APP) in the surrounding areas of rivers, with regard to their condition of preservation, and to verify the relation of this fact to the flooding events caused by intense rainfalls, using as an example the Macrozona 9 in Campinas - SP (MZ-9). This study involved the identification of the amount of flooding events which occurred by Basic Territorial Unit (UTB) in MZ-9, between 1980 and 2007, the delimitation and classification of APP, the elaboration of the Information Plan about the situation of APP, occurrences of flooding events by UTB and an analysis of how the municipal government deals with these issues related to the impacts of the rainfalls. The results show that mainly in sections where the APP are degraded, there is much more occurrence related to flooding, which reinforces the importance of Local Plans of
\end{abstract}

\footnotetext{
${ }^{1}$ Graduação em Ciências Biológicas (Licenciatura Plena e Bacharelado) pela Pontifícia Universidade Católica de Campinas, especialização em Formação de Educadores Ambientais pelo Coletivo Educador Ambiental de Campinas/ Fundo Nacional do Ministério de Meio Ambiente/ Universidade Estadual de Campinas, mestrado em Geografia pela Universidade Estadual de Campinas. Doutoranda em Geociências pela Universidade Estadual de Campinas. Técnica da Secretaria de Meio Ambiente da Prefeitura Municipal de Campinas. E-mail: angelaguirao@ige.unicamp.br

${ }^{2}$ Graduação em Geografia pela Universidade Estadual de Campinas - UNICAMP, Mestrado em Geografia e doutorando em Geografia pela Universidade Estadual de Campinas - UNICAMP. E-mail: marcelo.fonseca@ige.unicamp.br

${ }^{3}$ Graduação e Mestrado em Geografia pela Universidade Estadual de Campinas. Doutoranda do Departamento de Geografia da Universidade Estadual de Campinas. E-mail: marina.castellano@ige.unicamp.br DOI: 10.7154/RDG.2012.0024.0009
} 
Management to propose guidelines and measurements to reduce and solve such as these ones.

Key-Words: Precipitation; Social And Environmental Impacts; Urban Planning; Geoprocessing.

\section{INTRODUÇÃO}

As alterações verificadas no meio urbano são abordadas por diversos autores brasileiros (GRILO, 1993; SANT'ANNA NETO, 1998; MENDONÇA, 2000; BRANDÃO, 2001; YAHN e GIACOMINI, 2002; GONÇALVES, 2003; TUCCI, 2003; VICENTE, 2005; ACSELRAD, 2006; NUNES, 2008), sendo nestes espaços que os "problemas ambientais atingem maior amplitude" (LOMBARDO, 1985). Isso ocorre devido ao fato do processo de urbanização alterar uma série de elementos da paisagem, incluindo o solo, a vegetação, a geomorfologia, a fauna, a hidrografia e até o clima (BRAGA, 2003), por meio da substituição de áreas verdes por áreas construídas, alta concentração de indústrias, adensamento populacional, entre outros fatores. O alto grau de urbanização é uma realidade brasileira: segundo Maricato (2001), a população urbana no país passou de 18,8 milhões de habitantes em 1940 para 138 milhões no ano 2000, sendo que o último censo registrou uma população de aproximadamente 160 milhões de pessoas residentes em áreas urbanas (IBGE, 2010).

Devido a essas constantes alterações nas áreas urbanizadas, episódios de chuvas mais intensas podem provocar uma série de problemas à sociedade e ao poder público. Tais impactos não estão relacionados somente ao agente causador do desastre, mas sim aos aspectos socioeconômicos da população atingida (DEGG, 1992; LA RED, 1993; MATTEDI, 1999). Assim, deve se considerar tanto questões climáticas quanto sociais nas análises empreendidas, levando-se em conta as características de ocupação da terra, o planejamento de seu uso e as dinâmicas e particularidades locais.

Neste sentido, o papel do poder público municipal sobre o planejamento urbano e o ordenamento territorial é essencial, sobretudo no que diz respeito às inundações. Segundo Santos (2004), o planejamento:

(...) é um processo contínuo que envolve coleta, organização e análise sistematizadas das informações, por meio de procedimentos e métodos, para chegar a decisões ou a escolhas acerca das melhores alternativas para 
o aproveitamento dos recursos disponíveis. Sua finalidade é atingir metas específicas no futuro, levando à melhoria de uma determinada situação e ao desenvolvimento das sociedades (p. 24).

Para Braga (2003), as leis de uso e ocupação do solo, ferramentas do planejamento urbano, devem controlar o uso e a ocupação de áreas suscetíveis à inundação. São justamente nesses locais que são delimitadas as Áreas de Preservação Permanente (APP), definidas pelo Código Florestal (Lei Federal $n^{\circ} 4.771 / 65$, alterada pelas Leis $n^{\circ} 7.803 / 89$ e $n^{\circ} 7.875 / 89$ ) como áreas protegidas, "coberta ou não por vegetação nativa, com a função ambiental de preservar os recursos hídricos, a paisagem, a estabilidade geológica, a biodiversidade, o fluxo gênico de fauna e flora, proteger o solo e assegurar o bem-estar das populações humanas". Além do Código Florestal, as Resoluções CONAMA 302/02 e 303/02 também dispõem sobre parâmetros, definições e limites para as APP.A redução ou retirada total da vegetação em APP podem ter como consequência a ocupação irregular de áreas de várzea, o que pode acarretar na "redução do espaço natural destinado ao escoamento de vazões de enchentes" (ANDRADE; ROMERO, 2005, p. 14). Para Lewinsohn et al. (2005), essas áreas teriam papel fundamental no controle das inundações, funcionando como "piscinões", uma vez que elas "dissipam as forças erosivas do escoamento superficial das águas pluviais" (p. 3). Assim, a vegetação tende a aumentar o volume de água infiltrada no solo, diminuindo o escoamento superficial, que muitas vezes agrava o problema das inundações e seus impactos, principalmente à jusante. Outro ponto importante é que, com a vegetação presente nas APP, há uma menor chance de ocorrer erosão às margens dos cursos d'água, evitando assim a sedimentação acelerada e o consequente assoreamento desses rios, o que poderia diminuir a capacidade de vazão e aumentar as chances de inundação. Uma alternativa seria o uso das APP para compor os sistemas de áreas verdes e lazer nas áreas urbanas, proporcionando de forma natural a acomodação de volume de águas nos períodos de cheias e evitando transtornos e prejuízos à dinâmica urbana durante esses episódios (CAMPINAS, 1996).Por estes motivos, quando ocupadas as margens de cursos d'água, as APP se configuram como áreas de risco. Estima-se que no Brasil 5 milhões de pessoas morem nestas áreas (CAMPANERUT, 2011), sendo cerca de 5 mil habitantes em Campinas (CAMPINAS, 2006). É importante frisar que, na maioria das vezes, os residentes das áreas de risco são pessoas menos favorecidas economicamente, que se instalam nesses locais devido ao baixo 
valor dessas terras, geralmente renegadas pelo mercado imobiliário (TAUBE, 1986; MARICATO, 2000; SOUZA, 2006; FREITAS, 2007; MAFFRA e MAZZOLA, 2007).

Ao se deparar com esta problemática, torna-se extremamente pertinente e necessária a intervenção por parte do poder público na questão do planejamento das áreas de risco, por meio de ações estratégicas que possam minimizar os impactos advindos das chuvas, que comumente, são agravados pela falta de uma infraestrutura e/ou gestão urbana adequadas. Nesta perspectiva, alguns instrumentos podem ser utilizados como auxílio para a tomada de decisões no âmbito do planejamento, destacando o uso cada vez mais frequente do geoprocessamento, que se constitui um ramo do conhecimento atualmente aplicado com muita frequência nas investigações ambientais (XAVIER DA SILVA, 2001).

Segundo Câmara e Davis (2001), esta ideia é reforçada pelo fato de existir uma grande carência de informações adequadas para a tomada de decisões sobre os problemas urbanos e ambientais que afligem a maior parte das administrações municipais, principalmente em um país de grandes dimensões territoriais como o Brasil. Segundo os autores, o geoprocessamento apresenta um grande potencial para a geração de conhecimentos locais, preferencialmente através de alternativas que propiciem custos relativamente baixos. Desta forma, diversos fenômenos tipicamente geográficos podem ser interpretados com mais precisão e compreendidos a partir da geração de modelagens advindas do uso destas técnicas, o que pode vir a auxiliar o poder público na gestão efetiva das inúmeras demandas socioambientais existentes.

Diante do exposto, o objetivo principal deste artigo é analisar a situação das Áreas de Preservação Permanente no entorno de cursos d'água, no tocante a sua condição de preservação, e verificar a relação deste fato com os eventos de inundações - alagamentos de imóveis e vias - ocasionados por precipitações intensas, utilizando como exemplo o caso da Macrozona 9, no município de Campinas (SP).

\section{Área De Estudo}

O município de Campinas localiza-se no interior do estado de São Paulo, entre as latitudes $22^{\circ} 45^{\prime} 00^{\prime \prime}$ e $23^{\circ} 02^{\prime} 30^{\prime \prime} \mathrm{S}$ e as longitudes $466^{\circ} 50^{\prime} 00^{\prime \prime}$ e $47^{\circ} 15^{\prime} 00^{\prime \prime} \mathrm{W}$, apresentando uma área territorial aproximada de $887 \mathrm{~km}^{2}$, com cerca de 1.080.000 habitantes (IBGE, 2010), sendo sede da Região Metropolitana de Campinas (RMC). 
A cidade conheceu, ao longo de sua historia, um acelerado processo de crescimento, principalmente a partir da década de 1950 (CISOTTO, 2009). Este crescimento, muitas vezes desordenado e sem controle por parte do poder público municipal, teve como consequência a expulsão da população mais pobre para as áreas periféricas e o surgimento de favelas e ocupações irregulares, canalização de rios e aterramento de várzeas (CAIADO e PIRES, 2006; JACOBI, 2004).

Segundo o Plano Diretor de Campinas (Lei Complementar no 15 de 2006), em função do reconhecimento da heterogeneidade do território, a cidade foi dividida em 9 Macrozonas, considerando os aspectos físicos, socioeconômicos e ambientais. Cada Macrozona deve possuir um Plano Local de Gestão, que é uma ferramenta complementar de ordenamento do território a ser desenvolvido pelo poder Executivo com a participação da sociedade organizada (BERNARDO et al., 2006).

A Macrozona 9, objeto deste estudo, situa-se na porção noroeste do município, abrangendo as regiões do Distrito de Nova Aparecida e dos bairros Parque Santa Bárbara, Vila Boa Vista, Parque Via Norte, Amarais, Jardim São Marcos e Jardim Santa Mônica, conforme Figura 1 (CAMPINAS, 2010).

Com área de $28,79 \mathrm{~km}^{2}$, a Macrozona possui 75.747 habitantes (IBGE, 2000) e tem como usos principais o comércio, a indústria e habitações de média-baixa e baixa renda, que se concentram principalmente nos bairros Jardim São Marcos, Santa Mônica, Campineiro e Boa Vista, totalizando somente aí 16.645 habitantes (CAMPINAS, 2010).

A Macrozona 9 é drenada pelo ribeirão Quilombo e seus afluentes, e por uma porção da bacia do córrego Piçarrão. Embora a maioria das margens destes cursos d'água encontra-se degradadas e desprovidas de vegetação natural, elas possuem potencial de recuperação e formação de corredores ecológicos e implantação de áreas verdes (CAMPINAS, 2010). Cada Macrozona é dividida em Unidades Territoriais Básicas (UTB), referentes às menores células da divisão territorial do município, segundo o Plano Diretor de Campinas de 2006. Estas unidades "identificam-se através de bairros, ou conjuntos de pequenos bairros, configurando porções do espaço urbano que guardam significativo grau de homogeneidade quanto aos padrões (ou processos) de ocupação do solo e de níveis de renda" (CAMPINAS, 2006, p. 183). O mapa da Figura 2 apresenta o conjunto das UTB que fazem parte da Macrozona 9 e o seu respectivo número, dados pela administração municipal. 


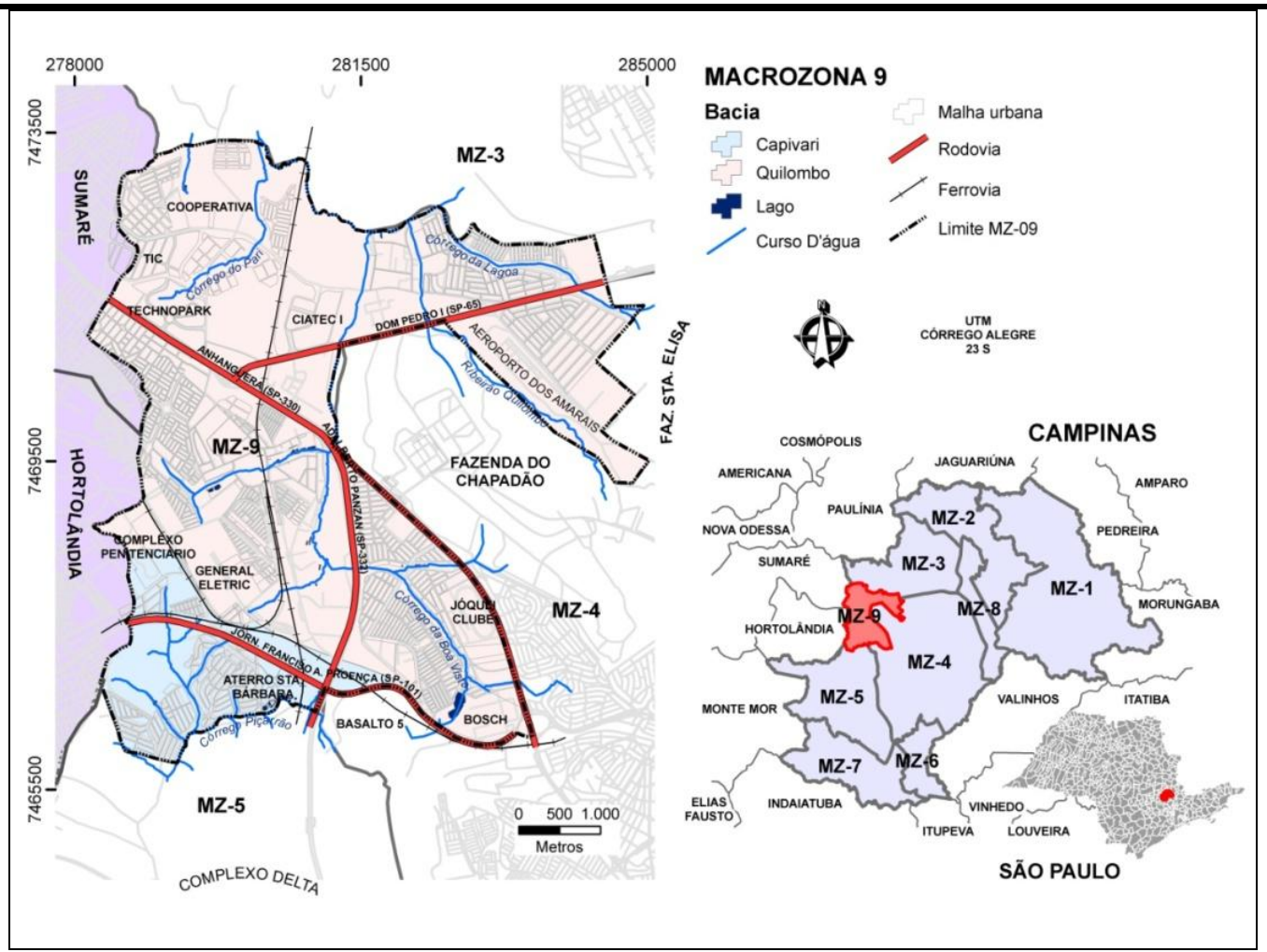

Figura 1. Localização da Macrozona 9, no município de Campinas. Fonte: Secretaria Municipal de Meio Ambiente, 2010.

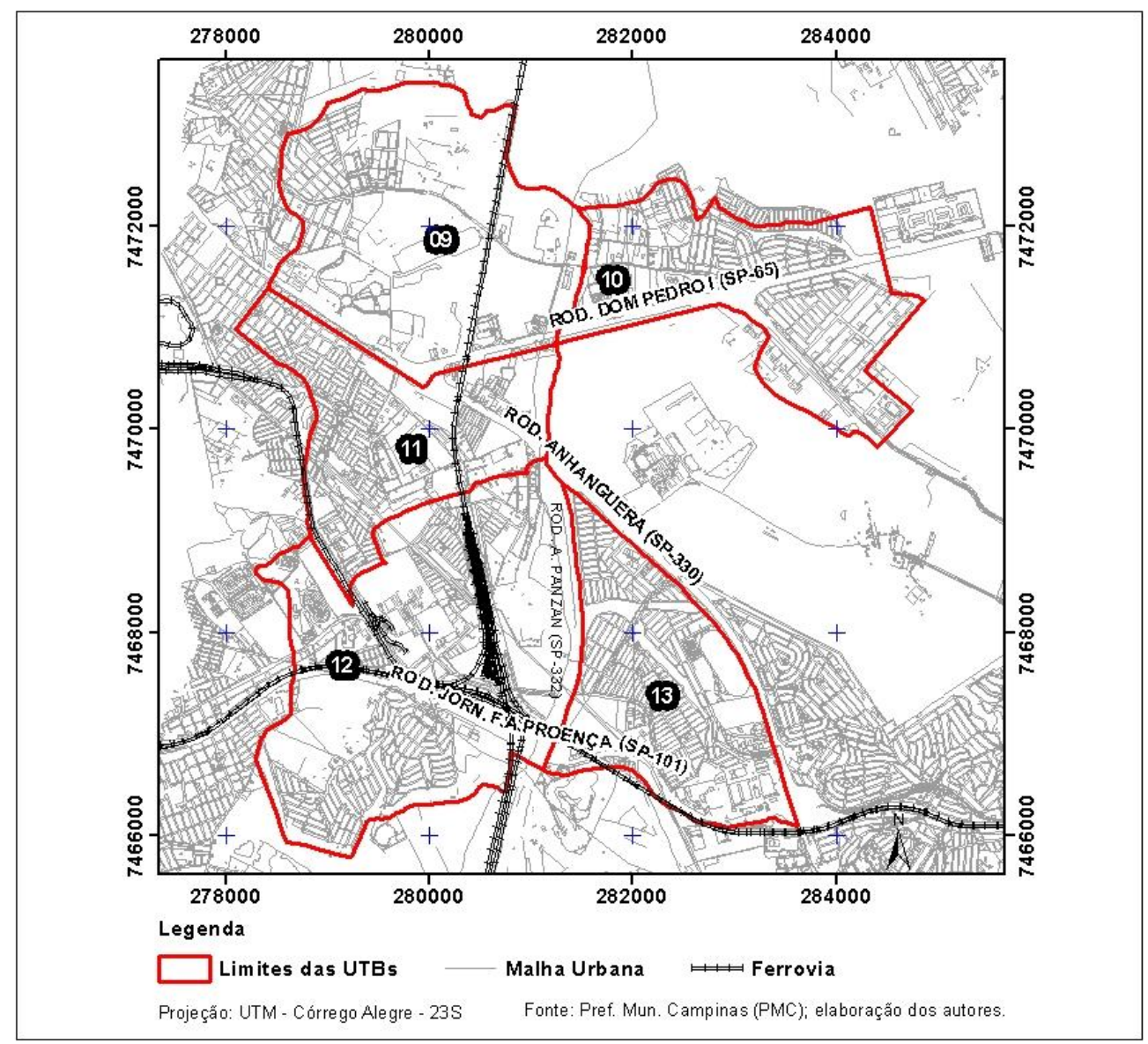

Figura 2. Mapa da Macrozona 9 e subdivisão por UTB (9 a 13) em Campinas (SP) 


\section{MATERIAL E MÉTODOS}

Para atingir os objetivos, este estudo considerou dados referentes às inundações, características do processo de urbanização vigente para a Macrozona 9, bem como a utilização, como suporte analítico, da aplicação de técnicas de geoprocessamento, sendo que os impactos identificados foram avaliados no âmbito do Plano Local de Gestão da Macrozona. Assim, foram etapas constituintes deste trabalho:

(1) Identificação da quantidade de eventos de inundação ocorridos por UTB na

\section{Macrozona 9}

Nesta etapa foram utilizados dados de Castellano (2010), referentes ao levantamento de impactos relacionados a eventos extremos de chuva entre os anos de 1980 e 2007 em Campinas. Estes dados foram adquiridos junto à Defesa Civil do município, assim como nos jornais Correio Popular, Diário do Povo (jornais locais), O Estado de São Paulo e Folha de São Paulo.

Dentre os impactos levantados, foram considerados apenas dois tipos: alagamentos de imóveis e vias, por estarem diretamente ligados às inundações em meio urbano, além de serem frequentes no município. Estas informações, organizadas em um banco de dados de acordo com as UTB em que ocorreram, propiciaram um panorama geral de quais áreas do município sofreram mais com as precipitações.

Devido à estes problemas de inundações serem frequentes na Macrozona 9, além de seu Plano Local de Gestão ter sido recém finalizado pela Prefeitura Municipal de Campinas, esta área foi escolhida como recorte para o presente estudo.

\section{(2) Delimitação das APP e classificação em remanescentes e degradadas}

Esta etapa do trabalho se deu a partir do mapa de Áreas de Preservação Permanente: Situação Legal, disponível no Caderno de Subsídios para o Plano Local de Gestão da Macrozona 9, material divulgado oficialmente pela administração municipal. Segundo dados da própria Prefeitura, para a elaboração deste mapa, foram considerados alguns parâmetros 
em função de características geográficas e legislação pertinente ao tema, conforme a Tabela 1.

Tabela 1. Classificação das APP utilizada pela Prefeitura Municipal de Campinas

\begin{tabular}{|c|c|c|}
\hline \multirow{2}{*}{$\begin{array}{c}\text { Ao longo dos rios ou de qualquer curso d'água desde o } \\
\text { seu nível mais alto em faixa marginal }\end{array}$} & $\begin{array}{c}\text { Largura do curso } \\
\text { d'água }\end{array}$ & Largura da APP \\
\cline { 2 - 3 } & Até 10 metros & 30 metros \\
\cline { 2 - 3 } & 10 a 50 metros & 50 metros \\
\hline $\begin{array}{c}\text { Ao redor das lagoas, lagos ou reservatórios d'água } \\
\text { naturais ou artificiais (áreas urbanas consolidadas) }\end{array}$ & --- & 30 metros \\
\hline Ao redor das nascentes & --- & 50 metros \\
\hline
\end{tabular}

As APP foram delimitadas segundo os critérios estabelecidos pelo Código Florestal (Lei Federal $n^{\circ}$ 4.771/65) e Resoluções CONAMA 302/02 e 303/02 e classificadas em dois grupos: (1) APP em conformidade com a legislação, ou seja, com cobertura vegetal e (2) APP em conflito com a legislação, ou seja, desprovida de vegetação e/ou ocupada por edificações ou outros usos diferenciados.

(3) Elaboração do Plano de Informação: análise da situação das APP e ocorrências de eventos de inundação, por UTB

De posse das informações levantadas e citadas acima, foi realizada a análise através de técnicas de geoprocessamento dos dados coletados junto ao mapeamento das APP, relacionada com a quantidade de ocorrências de eventos de inundação registrados em cada UTB. Tal procedimento foi realizado com o auxílio do software ArcGis $9.3^{\circ}$, onde foi constituída uma base de dados referentes à Macrozona 9 para fins de extração de áreas e espacialização dos eventos de alagamentos.

(4) Análise de como o poder público trata das questões associadas aos impactos de chuvas

A análise das ações propostas pelo poder público frente aos impactos relacionados às precipitações intensas e à ocupação e utilização das APP se deu por meio do Plano Local de Gestão da Macrozona 9, disponível no site da Prefeitura Municipal de Campinas. 


\section{RESULTADOS E DISCUSSÃO}

Os resultados obtidos apontam para uma diferenciação significativa em relação aos dados analisados para cada UTB da Macrozona 9, como pode ser observado na Tabela 2.

Tabela 2. Situação das APP no entorno de cursos d'água e eventos de inundação, por UTB

\begin{tabular}{|c|c|c|c|c|}
\hline $\begin{array}{c}\text { No } \\
\text { UTB }\end{array}$ & $\begin{array}{c}\text { Total de } \\
\text { nascentes }\end{array}$ & $\begin{array}{c}\text { APP Remanescente } \\
\mathbf{( \% )}\end{array}$ & $\begin{array}{c}\text { APP } \\
\text { Degradada } \\
(\mathbf{\%})\end{array}$ & $\begin{array}{c}\text { Ocorrências de alagamentos de } \\
\text { vias e imóveis (1980 a 2007) }\end{array}$ \\
\hline 9 & 2 & 38,44 & 61,56 & 1 \\
\hline 10 & 0 & 5,96 & 94,04 & 136 \\
\hline 11 & 1 & 9,58 & 90,42 & 26 \\
\hline 12 & 8 & 26,27 & 73,73 & $\mathbf{2 1 7}$ \\
\hline 13 & 2 & 9,69 & 90,31 & \\
\hline Total & $\mathbf{1 3}$ & $\mathbf{2 2 , 8 5}$ & $\mathbf{7 7 , 1 5}$ & \\
\hline
\end{tabular}

Percebe-se que há uma relação entre a quantidade de ocorrências relacionadas aos alagamentos e as condições das Áreas de Preservação Permanente: nas áreas onde as APP estão mais degradadas, as ocorrências de alagamentos de vias e imóveis foram mais recorrentes. No caso da UTB 10, por exemplo, mais de 94\% das APP estão desprovidas de vegetação, com o registro de 136 ocorrências, número superior ao verificado nas outras UTB. Estão localizados nesta UTB os bairros Jardim São Marcos, Santa Mônica e Campineiro, locais predominantemente ocupados por população de baixa renda, com casos identificados de ocupação irregular e onde parte dos moradores sofre frequentemente com as inundações do ribeirão Quilombo.

Já na UTB 9, da qual fazem parte, dentre outros, o bairro San Martin, verificou-se um número menor de ocorrências de alagamentos registrados, frente à identificação de uma maior área de APP preservada. O Mapa da Figura 3 apresenta a espacialização dos resultados para todas as UTB pertencentes à Macrozona 9. 


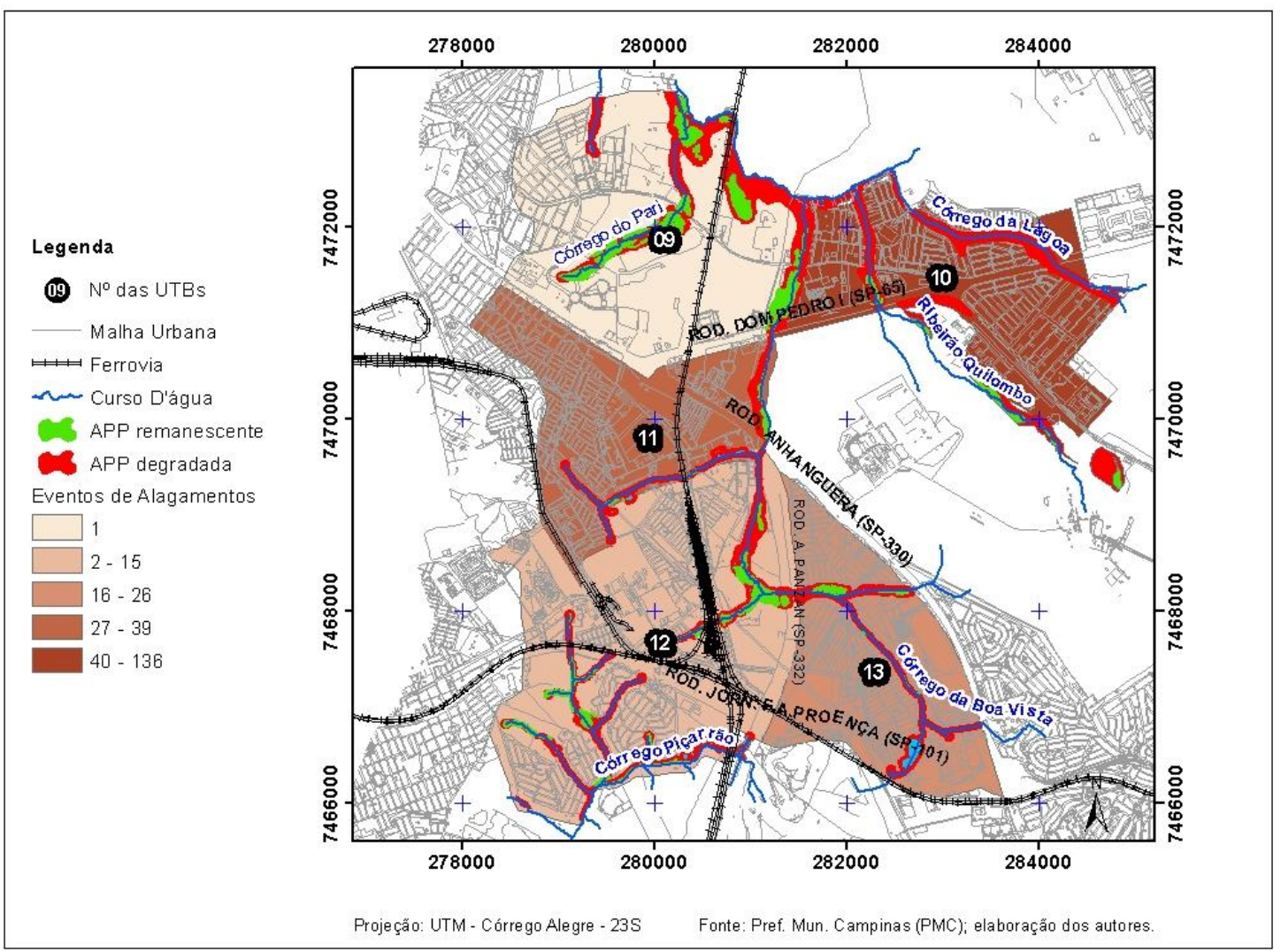

Figura 3. Mapa da Situação das APP e eventos de alagamentos, por UTB, Macrozona 9

Aventa-se, assim, que a relação entre a conservação e a manutenção das APP e os impactos ocasionados pelos eventos de precipitação intensa, aqui repercutidos através dos alagamentos, é real e direta para esta Macrozona. Todavia, é importante salientar que os eventos de alagamentos não ocorrem única e exclusivamente em virtude da degradação das APP: trata-se de um conjunto de fatores que podem influenciar negativamente na ocorrência destes fenômenos, sendo a ausência de vegetação, apenas um deles.

Os dados aqui apresentados apontam para a importância de discussões que envolvam formas adequadas de ocupação do território, o que sem dúvida nos remete ao debate do uso e ocupação da terra, e a mediação que o poder público pode e deve fazer em relação a isso. Como bem afirma Mendonça (2004), quando a dinâmica dos processos naturais é bruscamente alterada pelas atividades humanas (como mostra o processo de degradação das APP), os problemas socioambientais se acentuam (como no caso dos alagamentos de imóveis e vias) e acabam atingindo, em grande parte, os mais desprovidos de recursos econômicos, colocando boa parcela desta população em condições de risco e vulnerabilidade social. 
O Projeto de Lei Complementar (PLC) no 17/10, que dispõe sobre o Plano Local de Gestão da Macrozona 9 abrange diretrizes ambientais e habitacionais específicas focadas em programas e projetos de política habitacional que envolvem a remoção de famílias que ocupam áreas de risco e APP e a preservação de fragmentos de vegetação nativa e proteção dos recursos hídricos.

Dentre as diretrizes habitacionais estão a remoção de famílias que ocupam áreas de risco e inadequadas para habitação e diretrizes viárias do Ribeirão Quilombo (Região do São Marcos, Jardim Santa Mônica, Jardim Campineiro, Chácara Campo dos Amarais e Recanto da Fortuna). No Plano Local de Gestão da Macrozona 9 não são detalhados o número exato de famílias que serão removidas, o prazo e nem o local para onde serão encaminhadas. No entanto, estas ações deverão estar previstas em um decreto específico, a exemplo do Decreto Municipal $n^{\circ}$ 17.236/11 que dispõe sobre medidas preventivas e interdição de imóveis localizados em áreas sujeitas à inundação em alguns pontos do município de Campinas. Como auxílio aos moradores removidos, ficou autorizado o uso de imóveis públicos e requisição de imóveis particulares, para servirem temporariamente como abrigo à população, sendo de responsabilidade da Prefeitura Municipal, a alocação das pessoas removidas para os abrigos disponibilizados pela Administração. Às famílias removidas foi concedido Auxílio Moradia e feito o cadastramento no Programa do Governo Federal Minha Casa Minha Vida, desde que preenchidos os requisitos legais.

O Plano Local de Gestão da Macrozona 9 prevê a instituição de um Sistema de Áreas Verdes (SAV) que integre os remanescentes de vegetação nativa, APP, planícies de inundação, unidades de conservação, praças e parques públicos, abrangendo no mínimo $20 \%$ de sua área total. Entre os principais objetivos do SAV estão a preservação dos fragmentos de vegetação nativa e o patrimônio genético da fauna e flora regionais, proteção dos recursos hídricos, incluindo nascentes, cursos d'água, lagoas e várzeas e a requalificação da paisagem urbana e melhoria da ambiência. As recuperações das APP deverão estar condicionadas a um reflorestamento ciliar heterogêneo e integrado ao uso urbano do entorno com a implantação de áreas de lazer e recreação. Também será incentivada a implantação de dispositivos de armazenamento e utilização de águas pluviais nos empreendimentos que envolvam a impermeabilização do solo.

Estão previstos também o desassoreamento periódico das calhas dos canais dos córregos Quilombo, da Lagoa e Boa Vista, visando garantir as condições de escoamento na bacia e a 
implantação de estruturas ecológicas de controle da macrodrenagem, para disciplinar os processos de enchentes e prevenir a ocorrência de inundações em áreas habitadas ou sistema viário.

Outras importantes iniciativas municipais foram a criação da Lei Municipal n 10.729/00, que passou a exigir que novos loteamentos realizem e executem projeto de recuperação e/ou preservação ambiental das APP, e o Decreto Municipal 13.338/2000, que dispõe sobre a não incidência de IPTU para áreas com APP e/ou remanescentes florestais, desde que comprovada sua efetiva preservação. Assim, devem ser estendidos os efeitos da Lei no 10.729/00 para empreendimentos do tipo condomínios e conjuntos habitacionais.

Percebe-se, assim, que o Plano Local de Gestão para a Macrozona 9 leva em conta aspectos importantes na gestão das áreas de risco de inundação, abordando questões ambientais e sociais, essenciais para o entendimento e possível solução do problema, mas cabe destacar também a necessidade latente e irrestrita da participação popular como forma de fiscalizar e garantir o cumprimento destas metas e a implementação efetiva do referido Plano.

\section{CONCLUSÕES}

Os assuntos abordados neste trabalho nos remetem a destacar alguns aspectos importantes em relação aos problemas que são cada vez mais frequentes no meio urbano, ocasionados por um processo de urbanização intenso que, muitas vezes, ocorre sem o devido planejamento territorial.

Intimamente ligado a estes aspectos, estão as inundações, fenômenos naturais, mas que se tornam um grande problema em virtude dos impactos que trazem para a sociedade, sobretudo nas cidades. Percebe-se, portanto, que a questão está inevitavelmente ligada ao planejamento e ao uso e ocupação da terra. Assim, as ocupações irregulares de Áreas de Preservação Permanente precisam ser avaliadas sob a luz dos diversos aspectos indutores, pois este fato não está associado somente ao processo de invasão, geralmente por parte da população mais pobre, mas também à aprovação indevida de loteamentos, muitas vezes legitimada pelo poder público, à falta de uma legislação urbanística que estabeleça critérios claros para a gestão territorial e à falta de uma fiscalização atuante para que tais ocupações efetivamente não ocorram, dentre outros fatores. 
Neste sentido, os Planos Locais de Gestão são instrumentos importantes na minimização e resolução de problemas desta natureza. Cabe a eles revisar as diretrizes existentes, a realidade local, caracterizar a região e identificar as questões mais problemáticas. Outro ponto importante deste instrumento é a leitura e a proposição de ações para o território juntamente com a população diretamente envolvida.

É importante ressaltar também que as análises realizadas confirmam a eficiência do uso do geoprocessamento como instrumental auxiliar no apoio à tomada de decisão, provendo rapidamente informações para fins de planejamento territorial. A formação de uma base de dados socioambientais voltada para estudos do uso e ocupação da terra no meio urbano, com ênfase nos eventos de precipitação e suas inúmeras consequências, dentre as quais os fenômenos das inundações e alagamentos, pode ser extremamente útil para o entendimento e monitoramento dos eventos correntes, agregando sólidos benefícios ao processo de gestão municipal.

\section{REFERÊNCIAS BIBLIOGRÁFICAS}

ACSELRAD, H. As cidades e as apropriações sociais das mudanças climáticas. Cadernos IPPUR, Rio de Janeiro, v. 20 n. 1, p. 77-106, 2006.

ANDRADE, L.M.S. de; ROMERO, M.A.B. A importância das áreas ambientalmente protegidas nas cidades. In: XI Encontro Nacional da Associação Nacional de Pós-Graduação e Pesquisa em Planejamento Urbano e Regional - ANPUR, 23-27 de maio de 2005, Salvador, BA. Anais... Salvador: ANPUR, 2005.

BERNARDO, R.G.; STRUCHEL, A. C. O.; BITTENCOURT, L. C. O. Município de Campinas e os Planos Locais de Gestão Urbana. In: IV Congresso Brasileiro de Direito Urbanístico - Desafios Para o Direito Urbanístico do Século XXI, São Paulo, 2006. Anais... São Paulo: USP/ IBDU, 2006.

BRAGA, R. Planejamento Urbano e Recursos Hídricos. In: BRAGA, R; CARVALHO, P. F.C. de (Orgs). Recursos Hídricos e Planejamento Urbano e Regional. Rio Claro: Laboratório de Planejamento Municipal - Deplan/IGCE - UNESP, 2003, p. 113-127. 
BRANDÃO, A.M. de P.M. Clima Urbano e enchentes na cidade do Rio de Janeiro. In: GUERRA, A.J.T.; CUNHA, S.B. da. (Orgs). Impactos Ambientais Urbanos no Brasil. Rio de Janeiro: Bertrand Brasil, 2001,v.1, p. 47-109.

BRASIL. Lei $\mathrm{n}^{\circ} 4.771$ de 15 de setembro de 1965. Institui o novo Código Florestal. Diário Oficial da União. Brasília, 16 de setembro de 1965.

. Resolução CONAMA 302 de 20 de março de 2002. Dispõe sobre os parâmetros, definições e limites de Áreas de Preservação Permanente de reservatórios artificiais e o regime de uso do entorno. Diário Oficial da União. Brasília, 13 de maio de 2002.

. Resolução CONAMA 303 de 20 de março de 2002. Dispõe sobre parâmetros, definições e limites de Áreas de Preservação Permanente. Diário Oficial da União. Brasília, 13 de maio de 2002.

- Resolução CONAMA 369 de 28 de março de 2006. Dispõe sobre os casos excepcionais, de utilidade pública, interesse social ou baixo impacto ambiental, que possibilitam a intervenção ou supressão de vegetação em Área de Preservação PermanenteAPP. Diário Oficial da União. Brasília, 29 de março de 2006.

CAIADO, M.C.S.; PIRES, M.C.S. Campinas Metropolitana: transformações na estrutura urbana atual e desafios futuros. In: CUNHA, J.M.P. da. (Org.). Novas Metrópoles Paulistas População, Vulnerabilidade e Segregação. Campinas: Núcleo de Estudos de População Nepo/Unicamp, 2006, v.1, p.275-304.

CÂMARA, G.; DAVIS, C. Introdução. In: CÂMARA, G., DAVIS, C.; MONTEIRO, A.M.V. Introdução à ciência da geoinformação. São José dos Campos: INPE, 2001. p. 1-5. Disponível em: $<h t t p: / / m t c-$ m12.sid.inpe.br/col/sid.inpe.br/sergio/2004/04.22.07.43/doc/publicacao.pdf>. Acesso em: 23 de julho de 2011.

CAMPANERUT, C. Cerca de 5 milhões vivem em áreas de risco no Brasil, diz Mercadante; sistema de alerta deve ficar pronto em 4 anos. UOL Notícias, 17 de janeiro de 2011. Disponível em: <http://noticias.uol.com.br/cotidiano/2011/01/17/cerca-de-5-milhoes-vivem- 
area-de-risco-no-brasil-diz-mercadante-sistema-de-alerta-deve-ficar-pronto-em-4anos.jhtm>. Acesso em: outubro de 2011.

CAMPINAS. Lei $n^{\circ} 10.729$ de 20 de dezembro de 2000. Dispõe sobre a exigência de projeto de recuperação e/ou preservação ambiental em loteamentos que especifica. Diário Oficial de Campinas. Campinas, 21 de dezembro de 2000.

- Prefeitura Municipal de Campinas. Secretaria de Planejamento de Desenvolvimento Urbano. Plano Diretor. Campinas: SEPLAN, 1996, 291p. Disponível em: <http://www.campinas.sp.gov.br/governo/seplama/plano-diretor2006/doc/planodiretor1996.pdf>. Acesso em: 04 de dezembro de 2011. - Prefeitura Municipal de Campinas. Secretaria de Planejamento e Desenvolvimento Urbano. Plano Diretor. Campinas: SEPLAN, 2006, 476p. Disponível em: <http://2009.campinas.sp.gov.br/seplama/publicacoes/planodiretor2006/pd2006vfinal.htm> . Acesso em: 04 de agosto de 2011.

- Prefeitura Municipal de Campinas. Secretaria de Planejamento de Desenvolvimento Urbano. Caderno de Subsídios - Plano Local de Gestão da Macrozona 9. Campinas: SEPLAN, 2010, 255p. Disponível em: <http://www.campinas.sp.gov.br/governo/seplama/planos-locais-de-gestao>. Acesso em: 04 de agosto de 2011.

CASTELLANO, M.S. Inundações em Campinas (SP) entre 1958 e 2007: tendências sócioespaciais e as ações do poder público. 2010. 182f. Dissertação de Mestrado (Mestrado em Geografia) - Instituto de Geociências, Universidade Estadual de Campinas, Campinas: 2010.

CISOTTO, M.F. Natureza e Cidade: relações entre os fragmentos florestais e a urbanização em Campinas (SP). 2009. 260f. Dissertação de Mestrado (Mestrado em Geografia) Instituto de Geociências, Universidade Estadual de Campinas, Campinas: 2009.

DEGG, M. Natural Disasters: Recent trends and future prospects. Geography: Journal of the Geographical Association, v. 77, n.3, p. 198 - 209, julho de 1992. 
FREITAS, C.G.L. de (Coord.). Planos Diretores Municipais: Integração Regional Estratégica Roteiro Metodológico. 1 ed. Porto Alegre: ANTAC, 2007.Coleçao Habitare 7. 184p.

GONÇALVES, N.M.S. Impactos Pluviais e Desorganização do Espaço Urbano em Salvador. In: MONTEIRO, C.A de F.; MENDONÇA, F. Clima Urbano. São Paulo: Editora Contexto, 2003. 9. $69-91$.

GRILO, R.C. Clima Urbano: Proposta de Estudo sobre a precipitação. Boletim de Geografia Teorética, Rio Claro, v. 23, n. 45-46, p. 137-143, 1993.

INSTITUTO BRASILEIRO DE GEOGRAFIA E ESTATÍSTICA. <http://www.ibge.gov.br>. Censo de 2010. Acesso em: agosto de 2011.

JACOBI, P. Impactos ambientais urbanos- do risco à busca de sustentabilidade. In: MENDONÇA, F. (Org.) Impactos socioambientais urbano. Curitiba: Editora UFPR, 2004, p. 160-184.

LA RED - Red de Estudios Sociales en Prevención de Desastres en America Latina. Agenda de Investigación y Constitución Organica. Peru, 1993, 32p. Disponível em: <http://www.desenredando.org/public/libros/1992/agenda/AgendaDelnvestigacion1.0.0.pdf>. Acesso em: dezembro de 2011.

LEWINSOHN, T.M., METZGER, J.P.; JOLY, C.A.; CASATTI, L., RODRIGUES, R.R.; MARTINELLI, L.A. Impactos potenciais das alterações propostas para o Código Florestal Brasileiro na biodiversidade e nos serviços ecossistêmicos. Documento-síntese produzido por Pesquisadores do PROGRAMA BIOTA/FAPESP e pela ABECO (Associação Brasileira de Ciência Ecológica e Conservação). 2005. Disponível em: <http://www2.unesp.br/revista/wpcontent/uploads/2010/10/Biota-Fapesp-ABECO-Sintese-CFB-e-biodiversidade.pdf>. Acesso em: agosto de 2011.

LOMBARDO, M. A. Ilha de Calor nas Metrópoles - O Exemplo de São Paulo. São Paulo: Hucitec, 1985. 244p.

MAFFRA, C.Q.T.; MAZZOLA, M. As razões dos desastres em território brasileiro. In: SANTOS, R. F. dos. (Org.). Vulnerabilidade Ambiental. Desastres Naturais ou Fenômenos induzidos? Brasília: MMA, 2007, p. 9-12. 
MARICATO, E. As idéias fora do lugar e o lugar fora das idéias. Planejamento Urbano no Brasil. In: ARANTES, O.; VAINER, C.; MARICATO, E. A cidade do pensamento único Desmanchando consensos. Petrópolis, RJ: Editora Vozes, 2000, p. 121-192.

MARICATO, E. Brasil, Cidades. Alternativas para a crise urbana. Petrópolis: Editora Vozes, 2001, 2a Edição.

MATTEDI, M.A. As enchentes como tragédias anunciadas: impactos da problemática ambiental nas situações de emergência em Santa Catarina. 1999. 284f. Tese de Doutorado (Doutor em Ciências Sociais) - Instituto de Filosofia e Ciências Humanas, Universidade Estadual de Campinas, Campinas, 1999.

MENDONÇA, F. (Org.) Impactos socioambientais urbanos. Curitiba: Editora UFPR, 2004, $330 p$.

MENDONÇA, F. O Clima urbano de cidades de porte médio e pequeno: aspectos teóricometodológicos e estudo de caso. In: SANT'ANNA NETO, J. L.; ZAVATINI, J. A. (Orgs.). Variabilidade e Mudanças Climáticas - Implicações Ambientais e socioeconômicas. Maringá: EDUEM, 2000, p. 167-192.

NUNES, L.H. Critérios para a definição de eventos extremos - estudo de caso para o litoral central paulista. In: Simpósio Brasileiro de Climatologia Geográfica, 8, Alto Caparaó, 2008. Anais... Alto Caparaó, 2008. p. 295-311 (CD ROM).

SANT'ANNA NETO, J.L. Clima e Organização do Espaço. Boletim de Geografia. Universidade Estadual de Maringá, v. 16, n. 1, p. 119-131, 1998.

SANTOS, R.F. dos. Planejamento Ambiental - Teoria e Prática. São Paulo: Oficina de Textos, 2004.184p.

SOUZA, L.B. Instrumentos de planejamento e gestão urbanos em áreas de risco de escorregamentos. Geografia, Ageteo, Rio Claro, v. 31, n. 3, p. 677-686, set/dez 2006.

TAUBE, M.J. de M. De Migrantes a Favelados - Estudo de um Processo Migratório. Campinas: Editora da Unicamp, 1986. 219p. 
TUCCI, C.E.M. Coeficiente de Escoamento e Vazão Máxima de Bacias Urbanas. Revista Brasileira de Recursos Hídricos, Porto Alegre, v. 5, n.1, p. 61-68, jan/mar 2000.

. Processos Hidrológicos e os impactos do uso do solo. In: TUCCI, C.E.M.; BRAGA,

B. Clima e Recursos Hídricos no Brasil. Porto Alegre: ABRH, 2003, v.1., p. 31-76.

Água no meio urbano. In: REBOUÇAS, A da C.; BRAGA, B.; TUNISI, J.G. Águas

Doces no Brasil - Capital Ecológico, Uso e Conservação. São Paulo: Escrituras, p. 475-508, 2002.

VICENTE, A.K. Eventos Extremos de Precipitação na Região Metropolitana de Campinas. 2005. 143f. Dissertação de Mestrado (Mestrado em Geografia). Instituto de Geociências, Universidade Estadual de Campinas, Campinas, 2005.

XAVIER DA SILVA, J. Geoprocessamento para Análise Ambiental. Rio de Janeiro: Bertrand Brasil. 2001. 228p.

YAHN, A.G.; GIACOMINI, A.A.R.V. Recursos Hídricos e Saneamento. In: FONSECA, R. B.; DAVANZO, A.M.Q.; NEGREIROS, R.M.C. Livro verde: Desafios para a gestão da Região Metropolitana de Campinas. Campinas: Unicamp/IE, p. 195-223, 2002.

Artigo recebido em 24/05/2012.

Artigo aceito em 17/07/2012. 